\title{
Modelo multicritério para referência na fase de Projeto Informacional do Processo de Desenvolvimento de Produtos
}

\author{
Multicriteria model as a reference in the informational \\ design stage of the product development process
}

\author{
Elton Moura Nickel ${ }^{1}$ \\ Marcelo Gitirana Gomes Ferreira ${ }^{1}$ \\ Fernando Antônio Forcellini' \\ Célio Teodorico dos Santos ${ }^{1}$ \\ Ricardo Antônio Álvares Silva ${ }^{1}$
}

\begin{abstract}
Resumo: Este artigo compreende as etapas iniciais do Processo de Desenvolvimento de Produtos - mais especificamente a fase conhecida como Projeto Informacional -, considerando-as fundamentais para o sucesso de um novo produto no mercado. O fator complicador é que, durante essa fase do desenvolvimento, as diversas especificações e atributos do produto são definidos por se lidar com uma infinidade de critérios de escolha, com base nas necessidades dos clientes. Sendo assim, esta pesquisa visa propor uma nova sistematização da fase de Projeto Informacional, adequando-a aos métodos e ferramentas propostos pelas metodologias da decisão que tratam de problemas com múltiplos critérios, de modo a contribuir para a melhoria da prática de projeto nas suas fases iniciais. Com esse objetivo, desenvolve-se um modelo multicritério nos moldes do Modelo Unificado de Referência de Rozenfeld et al. (2006), ao propor métodos, ferramentas e documentos de apoio adequados ao cumprimento de cada atividade. As melhorias e os valores que a aplicação prática do modelo multicritério agrega ao Processo de Desenvolvimento de Produtos são discutidos mediante um estudo de caso referente ao projeto de produto comercial - um novo emissor de senhas.

Palavras-chave: Engenharia de produto e processo. Processo de Desenvolvimento de Produtos. Projeto Informacional. Abordagem multicritério.
\end{abstract}

\begin{abstract}
This paper includes the initial stages of the product development process - more specifically the stage known as Informational Design - considered to be fundamental to the success of a new product on the market. The complicating factor is that during this development stage the different specifications and attributes of the product are defined due to a multitude of choice criteria based on customer needs. Thus, this research aims to propose a new structure of the Informational Design stage by adapting it to the methods and tools offered by the methodologies of the decision that deal with multiple criteria problems in order to contribute to improve the initial stages of project practice. Hence, a multicriteria model based on the Unified Model by Rozenfeld et al. (2006) was developed to propose methods, tools, and supporting documentation appropriate to the achievement of each activity. The improvements and the values that the practical application of the multicriteria model adds to the Product Development Process were discussed through a case study carried of a commercial product development project - a new ticket dispenser.
\end{abstract}

Keywords: Product and process engineering. Product Development Process. Informational Design. Multicriteria approach.

\section{Introdução}

O projeto de um produto deveria se constituir em um processo sistematizado e, segundo Fonseca (2000, p. 51),

[...] Todo processo [de projeto] sistematizado se inicia com uma etapa obrigatória que consiste na familiarização com o problema que vai ser resolvido, procurando o maior volume de informação possível sobre o mesmo.

Essa árdua busca por informações, muitas vezes a atividade crítica em inúmeros projetos, é o que subsidiará as decisões mais importantes delegadas aos projetistas. Essa etapa tem como objetivo gerar

\footnotetext{
1 Departamento de Engenharia de Produção, Campus Universitário, Trindade, Universidade Federal de Santa Catarina - UFSC, CEP 88040-900, Florianópolis - SC, E-mails: eltonnickel@gmail.com; marcelo.gitirana@gmail.com; forcellini@deps.ufsc.br; celio@paradesign.com.br; ricardo@wmidia.com.br
}

Recebido em 19/10/2009 — Aceito em 23/11/2010

Suporte financeiro: CNPq. 
a 'matéria-prima' principal necessária para se obter, em etapas posteriores, as especificações do projeto e os atributos que o produto finalmente terá quando lançado no mercado.

Contudo, o desenvolvimento de novos produtos é uma atividade complexa, envolvendo uma série de necessidades e interesses. Muitas decisões ao longo do caminho devem ser tomadas, principalmente aquelas referentes à definição das especificações finais do produto, que repercutem nos interesses de todos os envolvidos no projeto. Consequentemente, recai sobre o projetista a responsabilidade de equilibrar todos esses critérios a fim de obter o resultado mais compensatório (BAXTER, 1995).

Recentemente têm-se desenvolvido estudos que visam formalizar e sistematizar o processo decisório, dos quais já emergiram metodologias direcionadas a trabalhar com problemas que envolvem múltiplos critérios de escolha. Proveniente da Pesquisa Operacional desenvolveu-se a abordagem multicritério que, dentre suas inúmeras aplicações científicas, também poderá ser útil frente a decisões complexas de projeto. Sendo assim, este artigo objetiva descrever os procedimentos adotados para a realização da fase de Projeto Informacional, sistematizada no Modelo Unificado de Referência de Rozenfeld et al. (2006), em situação real de projeto de um produto comercial.

No estudo de caso aqui descrito, os principais métodos e ferramentas da abordagem multicritério são utilizados, ao passo que as atividades do desenvolvimento são apresentadas com o intuito de verificar a viabilidade teórica e prática da proposta. Ao final do trabalho, é possível discutir os benefícios e/ou as vantagens que a abordagem multicritério e o foco no processo de tomadas de decisão oferecem para as primeiras etapas de projeto de produtos, especificamente a fase de Projeto Informacional.

\section{Revisão bibliográfica}

\subsection{Projeto Informacional}

Observa-se na literatura uma linha de procedimentos sistemáticos que envolvem as principais decisões de projeto de produtos quando o assunto é o levantamento e tratamento dos requisitos dos clientes. Geralmente essas atividades estão organizadas em uma fase de projeto denominada 'Projeto Informacional' (PI). Diversos autores, como Pugh (1990), Roozenburg e Eekels (1995), Baxter (1995), Pahl e Beitz (1996), Gomes Ferreira (1997), Fonseca (2000), Otto e Wood (2001), Rozenfeld et al. (2006), dentre outros, de maneira direta ou indireta, propõem as seguintes etapas principais apresentadas neste artigo: 'definição dos clientes'; 'identificação dos requisitos dos clientes'; 'conversão dos requisitos dos clientes em requisitos do produto' e 'obtenção das especificações de projeto'.
É importante destacar que o resultado final desses procedimentos são as especificações de projeto, que possuem dois principais objetivos: guiar as etapas seguintes do desenvolvimento do produto e servir de critério para as decisões tomadas ao longo do projeto.

A fase de Projeto Informacional (PI) do Modelo Unificado de Referência (MUR), de Rozenfeld et al. (2006), localizada na macrofase de Desenvolvimento do Produto, tem como objetivo final, a partir do levantamento e organização de informações oriundas de diversas fontes, desenvolver um conjunto de especificações-meta do produto, que servirão como critério de avaliação e de tomada de decisão em etapas posteriores do desenvolvimento. Daí sua importância para o sucesso de todo o processo. Um problema mal definido já nessa etapa inicial de desenvolvimento poderá comprometer todos os investimentos da empresa ou mesmo a não aceitação do produto no mercado ao qual ele se propõe a atender. As principais atividades da atual fase de PI estão organizadas na Figura 1.

É importante ressaltar que o modelo desenvolvido neste trabalho não tem por objetivo descaracterizar o Modelo Unificado de Referência, no sentido de eliminar, acrescentar ou substituir atividades da fase de Projeto Informacional. A contribuição para o processo se dá em um nível mais operacional, naquele relativo aos métodos, ferramentas e documentos de apoio utilizados para o cumprimento de cada atividade.

Além do mais, nem todas as atividades sofrem intervenções, apenas aquelas destacadas na Figura 1, a saber: 'Identificar os requisitos dos clientes do produto', 'Definir requisitos de projeto do produto' e 'Definir especificações-meta do produto'. Essas são as atividades, identificadas em revisão bibliográfica, que envolvem situações críticas de decisão. O objetivo dos autores, portanto, não é utilizar a abordagem multicritério, com todos os seus procedimentos padrões, para realizar o projeto de um produto, mas sim propor uma nova sistematização do Projeto Informacional do PDP, adaptando e incorporando as melhores práticas da abordagem multicritério, de modo que a base do trabalho seja a Gestão do Desenvolvimento de Produtos, não a Pesquisa Operacional ou qualquer outra área.

\subsection{Abordagem multicritério}

Em 1960 foi introduzida a 'teoria da decisão' por Howard Raiffa e Robert Schlaifer, da Harvard University's Business School. Desde então, o que não passava de mais uma abstrata disciplina matemática tem sido promovida para um potencial uso tecnológico conhecido como análise da decisão. O sucesso de tal desenvolvimento ficou evidente por inúmeras aplicações em diferentes campos da atividade humana, como o comércio, o governo e a medicina. 


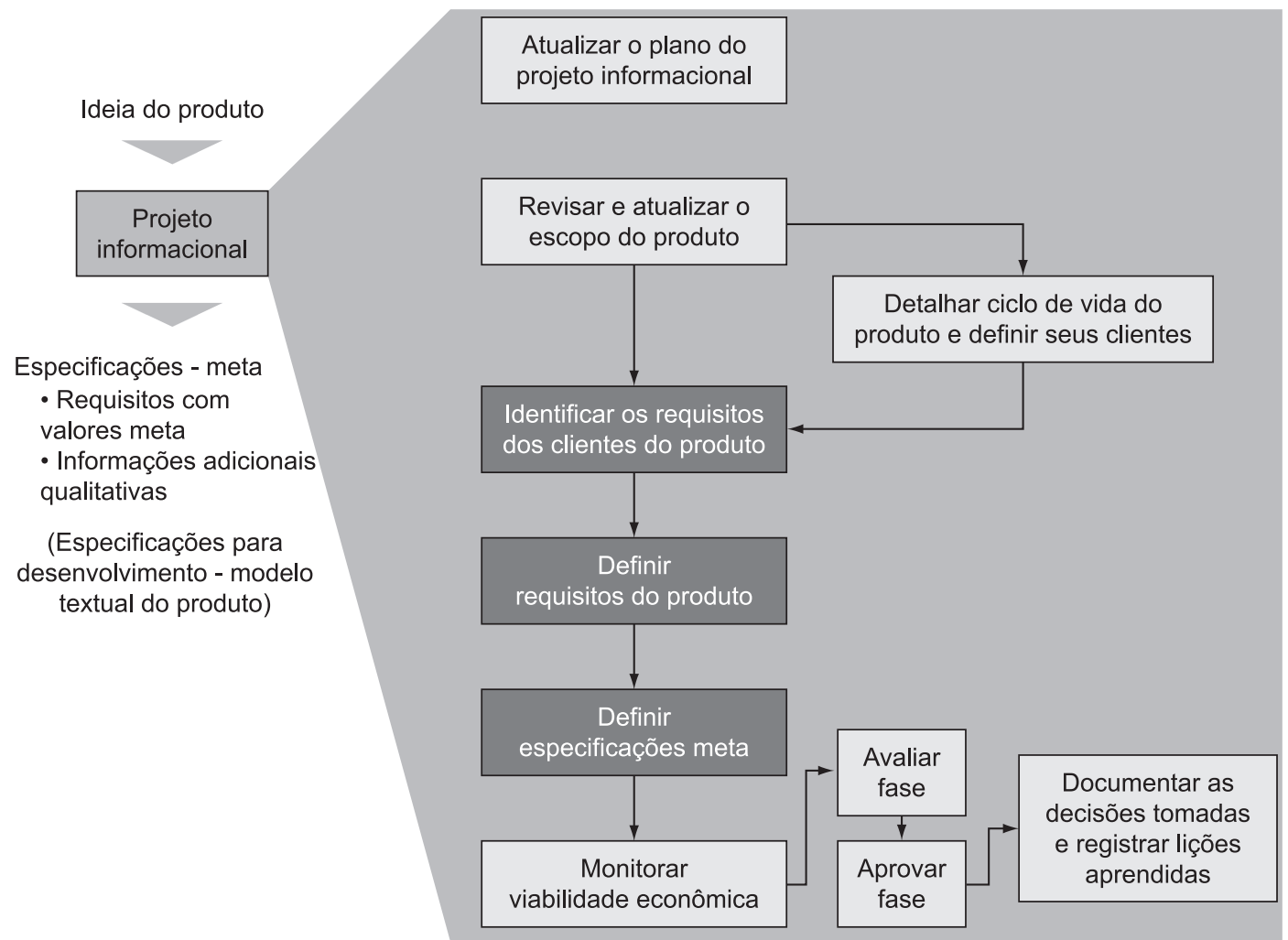

Figura 1. Informações principais e dependência entre as principais atividades da fase de Projeto Informacional do MUR (ROZENFELD et al., 2006).

(GOODWIN; WRIGHT, 1998). Mais recentemente, os estudos a respeito do processo decisório fizeram emergir metodologias direcionadas a trabalhar com problemas que envolvem múltiplos critérios. Com o objetivo de expandir o conhecimento aplicado pela Pesquisa Operacional tradicional, até então, desenvolveu-se a abordagem multicritério, na qual o responsável por tomar decisões deveria equilibrar suas próprias preferências, a fim de atingir possíveis consequências ou resultados. A preocupação das metodologias multicritério, em contraste com as tradicionais monocritério, é como um indivíduo, ou grupo de indivíduos, pode fazer sentido aos seus valores conflitantes, objetivos, metas e chegar a uma decisão acertada (KEENEY; RAIFFA, 1993).

A abordagem multicritério tem-se desenvolvido a partir de duas escolas principais, uma conhecida como MCDM (Multicriteria Decision Making), de origem americana e visão objetivista; e outra conhecida como MCDA (Multicriteria Decision Aid), de origem europeia e visão subjetivista. Raiffa (1977, p. 16) aponta certas diferenças entre as duas correntes teóricas ao afirmar que

[...] os 'subjetivistas' desejam introduzir julgamentos e sensações intuitivas, diretamente na análise formal do problema de decisão .
Já os 'objetivistas', segundo o autor,

[...] acham que esses aspectos subjetivos devem ser deixados fora da análise formal, e que se forem usados, o sejam apenas para ligar, ao mundo real, os resultados objetivos que são obtidos pelo uso de um modelo formal (RAIFFA, 1977, p. 16).

Convém destacar que o mais importante não é rotular ou localizar o modelo desenvolvido neste trabalho em determinada metodologia ou escola. O objetivo é absorver e experimentar procedimentos e técnicas provenientes das metodologias do processo decisório, de abordagem multicritério, que uma vez adaptadas, sirvam para agregar valor e aprimorar o processo de desenvolvimento de novos produtos.

\section{Desenvolvimento}

O estudo de caso é iniciado com a análise do problema de projeto. O produto que servirá de exemplo para a aplicação do modelo multicritério foi denominado de DASIII (Dispositivo Automático de Senhas III), atualmente já comercializado pela Specto Painéis Eletrônicos Ltda., empresa de tecnologia com sede na cidade de Florianópolis, Estado de Santa Catarina.

$\mathrm{O}$ projeto em questão teve suas principais fases de desenvolvimento realizadas em julho e agosto de 
2008, momento em que se pôde registrar e tabular as informações e o conhecimento construído ao longo do projeto. $\mathrm{O}$ trabalho foi realizado junto à equipe de desenvolvimento da Paradesign Desenhos Ltda., escritório de design também com sede na cidade de Florianópolis, a qual possui a Specto como um de seus clientes e parceiros (STEPHAN et al., 2008).

O projeto do DASIII se iniciou após a empresa Specto ter vencido um pregão eletrônico de um determinado banco do País. Possuindo um prazo exíguo para a entrega do primeiro lote de emissores de senha, a empresa necessitava desenvolver o projeto levando em conta os aspectos funcionais, estéticos e simbólicos desejados tanto pelo banco quanto pela própria Specto, em virtude do interesse de também adicionar o DASIII ao portfólio de produtos da empresa, destinado ao mercado interno e externo. Outras necessidades explícitas para o projeto eram a máxima redução de custos e a meta de aproveitar a própria cadeia de fornecedores da Paradesign.

\subsection{Identificar os requisitos dos clientes do produto}

A Figura 2 descreve o modelo multicritério da atividade de 'Identificar os requisitos dos clientes do produto' do Projeto Informacional. Como se pode ver, a atividade de identificar os requisitos dos clientes é cumprida por meio de quatro tarefas: 'Coletar as necessidades dos clientes de cada fase do ciclo de vida'; 'Agrupar e classificar as necessidades'; 'Definir requisitos dos clientes'; e 'Valorar requisitos dos clientes'. Na Figura 2, que contém a primeira atividade do modelo, já se percebe que os meios para se cumprir cada atividade são as tarefas. Os meios para se cumprirem as tarefas são os métodos, ferramentas e documentos de apoio que, por sua vez, podem ser obtidos por meio da literatura.

No início da primeira tarefa, as informações que já estão disponíveis, obtidas nas atividades anteriores, são: a declaração do escopo do produto; o ciclo de vida do produto; e os clientes do produto. Por outro lado, a informação gerada ao final da atividade serão os requisitos dos clientes.

Para a primeira tarefa de 'Coletar as necessidades dos clientes de cada fase do ciclo de vida', propôs-se a obtenção dos valores dos clientes, pois, segundo Keeney (1992, p. 1), as alternativas para se solucionar um problema

[...] são relevantes apenas porque elas são recursos para alcançar seus valores. Assim, o seu primeiro pensamento deve centrar-se em valores e, mais tarde, alternativas que possam alcançá-los.

De modo que os valores dos clientes, expressos em necessidades, constituem o alicerce do Projeto Informacional. Contudo, como obter informações tão subjetivas de um público tão amplo, como o mercado consumidor? Em um projeto piloto, utilizando a metodologia MCDA, publicado em 2008, realizou-se a experiência de obter as necessidades de um personagem símbolo, um indivíduo que representasse o públicoalvo do produto em questão. Porém, a sugestão final do trabalho, quanto a esse assunto, foi a de aplicar questionários e entrevistas em um cenário com diversos decisores de compra, pois tal procedimento aumentaria

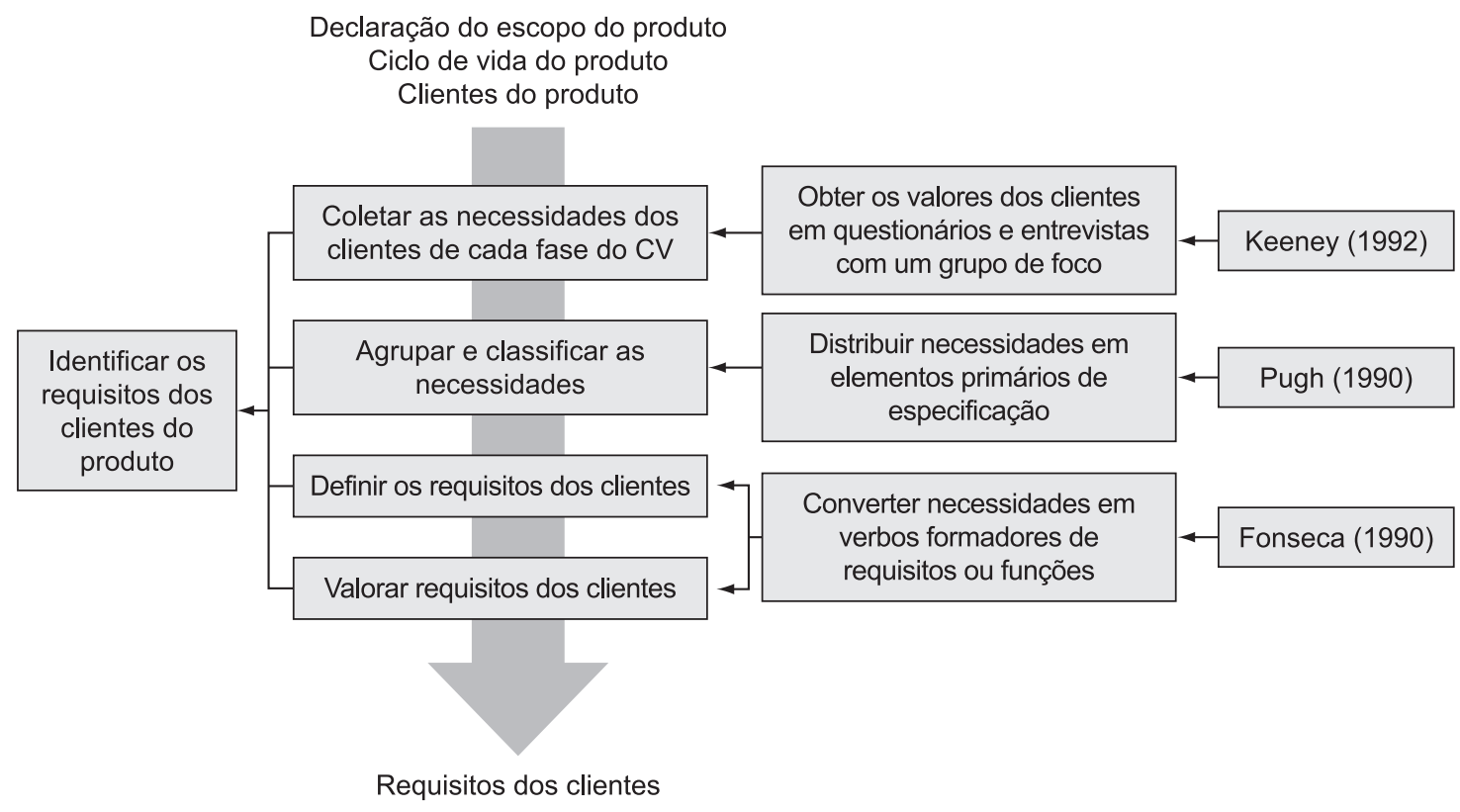

Figura 2. Atividade de 'Identificar os requisitos dos clientes do produto' com abordagem multicritério. 
as chances de as preferências do público-alvo estarem melhor representadas (BALBIM et al., 2008a, b).

Portanto, a proposta para esse levantamento de necessidades por meio dos valores é a implementação de um grupo de foco. O grupo de foco (ou focus group) envolve a seleção de um grupo de cinco a nove consumidores e realiza-se, em ambiente controlado, uma dinâmica de grupo em que os clientes são estimulados a reagir diante dos produtos e são avaliados seus comportamentos, comentários e sugestões (AAKER; KUMAR; DAY, 2001). O objetivo dessa pesquisa qualitativa, segundo Baxter (1995), é obter a percepção aprofundada da necessidade de mercado de um pequeno número de consumidores, ao passo que tal autor também sugere o número aproximado de cinco pessoas para o grupo pesquisado.

Para o projeto do DASIII, basicamente, dois grupos de foco foram considerados: 1) representantes da empresa Specto, ao levarem em consideração as necessidades dos clientes intermediários e internos; e 2) representantes do banco adquirente, ao levarem em consideração as necessidades dos clientes externos. De ambos os grupos foi possível captar os aspectos considerados mais importantes para o projeto do emissor de senhas. Os valores, ou necessidades, de cada um dos grupos foram os seguintes:

- Clientes Externos: 1 - Enxergar facilmente onde retirar a senha; 2 - Ser confortável para retirar a senha; 3 - Fácil leitura das opções de atendimento; 4 -A impressora deve estar oculta no produto; 5 - O produto deve ter 8 opções de atendimento; 6 - Deve-se usar a melhor alternativa para acionamento; 7 - O pedestal deverá ter a possibilidade de fixação no chão; 8 - Facilidade de manutenção; 9 - Fácil reciclagem do produto; 10 - O produto deve ser resistente a desgaste; 11- O produto não pode ocupar muito espaço no banco; 12 - O produto deve usar as cores do banco; 13 - Evitar visualização de periféricos; 14 - Evitar abertura indevida do produto.

- Clientes Intermediários e Internos: 1 - Baixo custo de fabricação; 2 - Deve-se usar a melhor opção de impressora; 3 - O produto deve ser o mais leve possível; 4 -É bom que seja fácil de montar e desmontar; 5 -A estrutura do produto deverá ser simples; 6 - Mínimo possível de peças; 7 - O transporte do conjunto deve ser fácil; 8-O armazenamento deve ser facilitado; 9 - A matéria-prima deve ser boa e barata; 10 - Que o produto tenha a aparência de 'moderno'.

Na medida em que um conjunto amplo e suficiente de necessidades já foi obtido, passa-se para a segunda tarefa da atividade, que é a de agrupar e classificar essas necessidades, para que a equipe de projeto possa verificar as necessidades similares e eliminar as repetições e as necessidades pouco relevantes para o projeto. Conforme a Figura 2, o meio proposto para cumprir essa tarefa é distribuir as necessidades em Elementos Primários de Especificação (PUGH, 1990). Esses elementos devem ser levados em consideração quando da triagem das necessidades, pois, segundo o autor, agem como um manto envolvendo o núcleo central de atividades do projeto. Desse modo, para as necessidades dos clientes externos, obtiveram-se quatro Elementos Primários de Especificação: 'Ergonomia', 'Normas', 'Desempenho', e 'Meio Ambiente'. Para as necessidades dos clientes intermediários e internos, obtiveram-se dois Elementos Primários de Especificação: 'Armazenamento e Transporte' e 'Eficiência'.

Uma vez realizados o agrupamento, a análise e a classificação das necessidades, elas devem ser reescritas na forma de requisitos dos clientes, em função de estarem inicialmente descritas segundo a linguagem deles. Esse refinamento, como a terceira tarefa da atividade abordada, permitirá que a equipe de projeto trabalhe melhor com as informações obtidas, em uma linguagem de projeto, relacionando os requisitos com aspectos tais como: desempenho funcional, fatores humanos, propriedades, espaço, confiabilidade, ciclo de vida, recursos e manufatura (ROZENFELD et al., 2006).

Segundo Fonseca (2000), uma forma simples para converter as necessidades em requisitos dos clientes, é a seguinte: todo requisito de usuário é 1) uma frase curta composta pelos verbos ser, estar ou ter, seguida de um ou mais substantivos, ou 2) uma frase composta por um verbo que não seja ser, estar ou ter, seguida de um ou mais substantivos, denotando, neste caso, uma possível função do produto.

Este procedimento é apresentado a seguir, tomando como exemplo as três necessidades pertencentes ao elemento "Ergonomia":

1) Enxergar facilmente onde retirar a senha ("Ter fácil visualização da senha");

2) Ser confortável para retirar a senha ("Ser confortável para retirar a senha"); e

3) Fácil leitura das opções de atendimento ("Ser de fácil leitura").

Finalmente, a atividade de identificar os requisitos dos clientes do produto é concluída com a tarefa de 'valorar requisitos dos clientes'. É fundamental destacar que o cumprimento dessa tarefa é desnecessário para o modelo proposto, haja vista que a usual ferramenta QFD será suprimida neste trabalho. Tal valoração é necessária apenas para a inserção dos graus de preferências dos clientes na matriz da casa da qualidade e, apesar de a tarefa ter sido mantida no esquema gráfico para manter o arranjo original, não 
oferece maiores benefícios para o modelo multicritério em questão.

\subsection{Definir requisitos de projeto do produto}

O esquema gráfico, ou mapa mental, da segunda atividade da fase de Projeto Informacional contemplada com a abordagem multicritério pode ser observado na Figura 3. Trata-se da atividade de 'Definir requisitos de projeto do produto'. Observa-se que as principais informações de entrada para essa atividade são os 'requisitos dos clientes', obtidos na atividade anterior. $\mathrm{Na}$ outra extremidade, o principal resultado ou entrega são os 'requisitos do produto'.

$\mathrm{O}$ método utilizado neste modelo para cumprir a primeira tarefa, ou seja, converter requisitos dos clientes em expressões mensuráveis é proposto por Roozenburg e Eekels (1995), com base nos estudos de Keeney (1992). Trata-se, justamente, da utilização de mapas mentais em cadeias de meios e fins.

Uma cadeia de meios-fins consiste num conjunto de objetivos, cada um dos quais pode ser visto como um meio para atingir um fim ou uma causa de um efeito. Desta maneira, os níveis inferiores do mapa normalmente são objetivos mais operacionais e mais fáceis de medir (ROOZENBURG; EEKELS, 1995).

Para cada um dos Elementos Primários de Especificação e seus respectivos requisitos dos clientes, obteve-se um mapa mental. Com esse procedimento, geraram-se 28 requisitos do produto a partir de 24 requisitos dos clientes. Além disso, com os demais elementos que compõem os mapas mentais, foi possível compreender melhor o que os clientes queriam dizer com as necessidades manifestadas na pesquisa, bem como seus objetivos principais com o produto.

Por exemplo, ao contemplar os requisitos dos clientes externos, no mapa mental de 'Ergonomia' obtiveram-se 6 requisitos do produto a partir de 3 requisitos dos clientes, conforme a Figura 4.

Portanto, o método das cadeias de meios e fins tem como um dos resultados mais importantes a obtenção dos objetivos primários, ou operacionais, aqueles que contribuem pontualmente para a solução de um problema global, por meio de pequenas soluções locais. Pela análise dos mapas mentais obtidos no projeto até este momento, pode-se iniciar a segunda tarefa da atividade, ou seja, 'analisar e classificar os requisitos do produto'. Para este fim, propõe-se a estruturação do modelo por meio da construção de 'árvores de valor' em 'hierarquia de objetivos' (KEENEY, 1992; GOODWIN; WRIGHT, 1998).

Para Keeney (1992), o processo de estruturação de objetivos resulta em uma compreensão mais profunda e mais precisa a respeito do que deve ser de preocupação no contexto da decisão. A estruturação ajuda a esclarecer o contexto de decisão e a definir o conjunto de objetivos fundamentais. Isto leva a uma distinção mais clara entre os objetivos fundamentais e os objetivos meios.

Para determinar a hierarquia dos objetivos existentes nessa estrutura, obtiveram-se as "taxas de substituição", ou seja, o valor relativo que o cliente atribui a cada um dos objetivos da cadeia (KEENEY; RAIFFA, 1993). A árvore de valor do projeto do DASIII e as respectivas taxas de substituição do modelo, construídas pela Paradesign em conjunto com os grupos de foco do projeto, encontram-se na Figura 5.

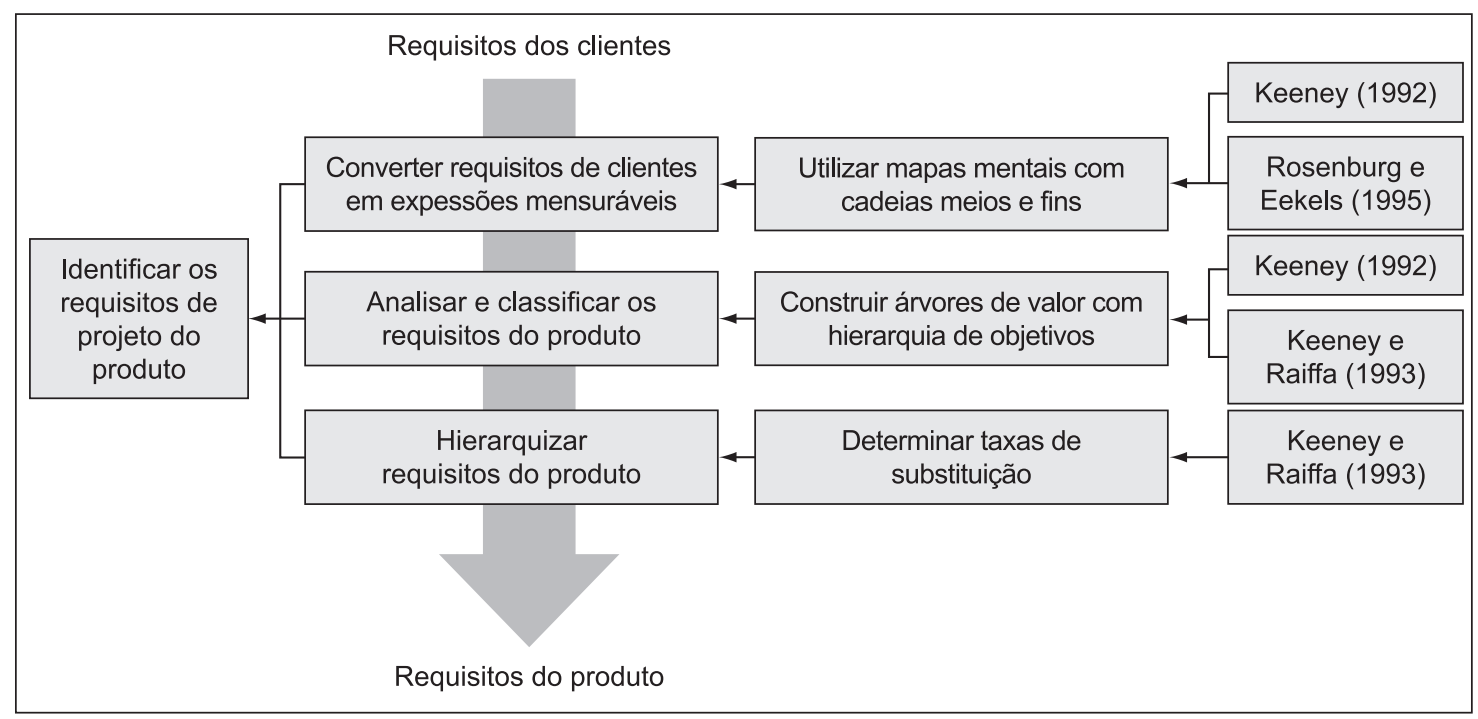

Figura 3. Atividade de 'Definir requisitos de projeto do produto' com abordagem multicritério. 


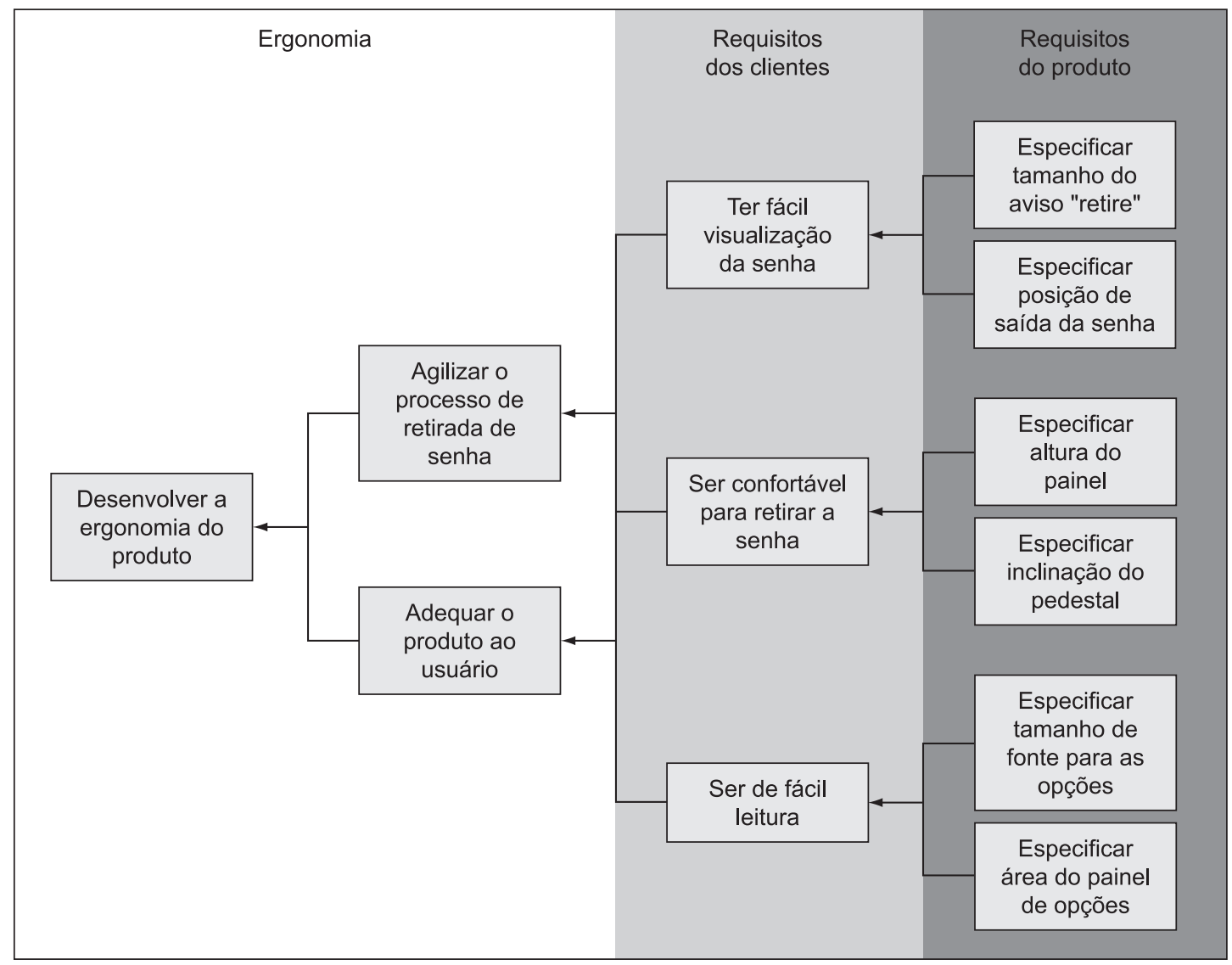

Figura 4. Mapa mental de 'Ergonomia'.

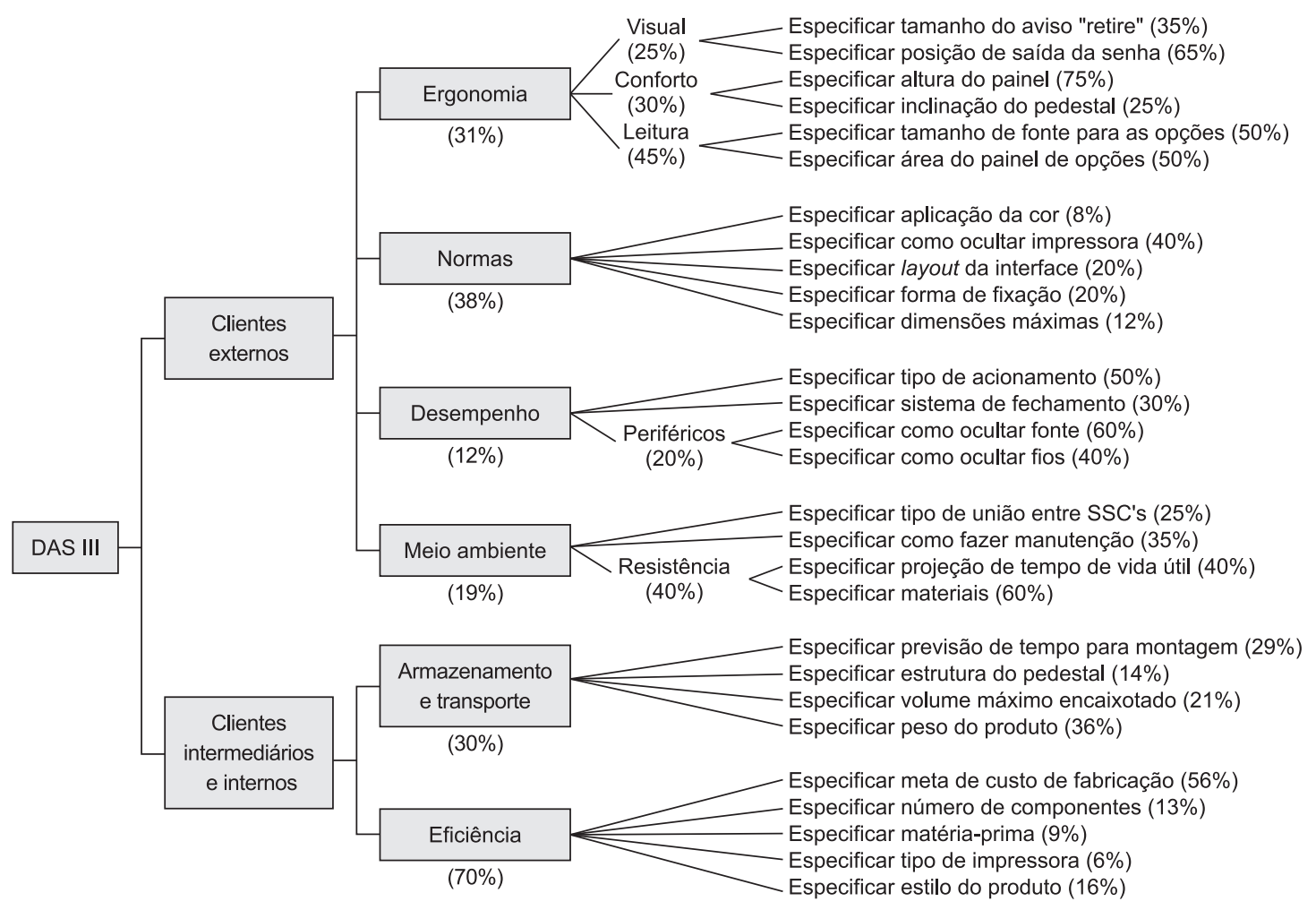

Figura 5. Árvore de valor e taxas de substituição do projeto DASIII. 
Keeney e Raiffa (1993) sugerem cinco critérios que podem ser usados para julgar a árvore de valor, objetivando sua correta construção: exaustividade, operacionalidade, decomposabilidade, ausência de redundância e tamanho mínimo. Com relação aos objetivos constituintes de uma árvore de valor, Keeney (1992) os classifica em 'objetivos fundamentais' e 'objetivos meio', seguindo uma lógica parecida com a existente na estrutura de cadeias de meios e fins. Além disso, Keeney (1992) orienta para que os objetivos utilizados em um modelo formal tenham as seguintes características: sejam essenciais; controláveis; completos; mensuráveis; operacionais; possam ser decompostos; não redundantes; concisos; e compreensíveis.

A terceira e última tarefa da atividade em questão diz respeito a hierarquizar os requisitos do produto, já obtidos com os mapas mentais e organizados na árvore de valor. Esse objetivo pode ser alcançado com a determinação das 'taxas de substituição', conforme exposto na figura anterior. Para Keeney e Raiffa (1993), o conceito de taxa de substituição é a recíproca negativa da inclinação da curva de indiferença. Em termos simples, trata-se da compensação que ocorre quando se atribuem valores percentuais a cada um dos objetivos da árvore de valor. Sendo assim, a soma das taxas pertencentes aos objetivos relativos deve sempre ser igual a $100 \%$.

As taxas de substituição podem ser aferidas diretamente. Contudo, para facilitar a distribuição de valores para três ou mais objetivos relativos, sugere-se a utilização de um procedimento sistematizado para essa etapa do projeto. Um desses procedimentos é o diagrama de Mudge (ROZENFELD et al., 2006), apresentado na Figura 6, na qual se exemplifica a obtenção das taxas de substituição dos objetivos relativos à 'eficiência'. A vantagem em se utilizar o diagrama de Mudge reside no fato dele dispensar o uso de softwares comerciais.

Nesse diagrama a valoração é feita comparando-se os objetivos aos pares e obtendo-se um ranking, ou hierarquia, dos objetivos e o quanto cada um deles é mais ou menos importante para o cliente. Durante as comparações são feitas as seguintes perguntas: "Qual requisito é mais importante para o sucesso do produto? Quanto mais importante é esse requisito?"

\begin{tabular}{|c|c|c|c|c|c|c|c|}
\hline 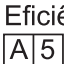 & & 2 & 3 & 4 & 5 & Soma & $\%$ \\
\hline \begin{tabular}{|l|l|} 
B & 4 \\
\end{tabular} & \multirow[t]{6}{*}{1} & $1 \mathrm{~B}$ & $1 \mathrm{~A}$ & $1 \mathrm{~A}$ & 1B & 18 & 56 \\
\hline \begin{tabular}{|l|l|}
$C$ & 3 \\
\end{tabular} & & 2 & $2 \mathrm{D}$ & $2 \mathrm{D}$ & $5 \mathrm{C}$ & 4 & 13 \\
\hline \begin{tabular}{|l|l}
$\mathrm{D} 2$ \\
\end{tabular} & & & 3 & $4 \mathrm{D}$ & $3 \mathrm{C}$ & 3 & 9 \\
\hline \multirow[t]{3}{*}{\begin{tabular}{|l|l|}
$\mathrm{E}$ & 1 \\
\end{tabular}} & & & & 4 & $5 D$ & 2 & 6 \\
\hline & & & & & 5 & 5 & 16 \\
\hline & & & & & Total & 32 & 100 \\
\hline
\end{tabular}

Figura 6. Diagrama de Mudge.
(ROZENFELD et al., 2006, p. 222). Especificamente na Figura 6, a combinação de número/letra nos campos centrais representa qual objetivo é predominante e a intensidade de importância. Por exemplo, onde aparece '1B', logo no primeiro campo, quer dizer que o objetivo ' 1 ' prevalece sobre o objetivo '2' com uma intensidade '4' ('B'), conforme a legenda. Nas duas últimas colunas, obtém-se o ranking dos objetivos, ou seja, seus respectivos graus de importância. Estes graus de importância passam a ser entendidos como 'taxas de substituição' na medida em que se obtêm os valores percentuais dos objetivos. O objetivo ' 1 ' é o mais importante, com uma taxa de substituição de $56 \%$, seguido dos objetivos ' 5 ', '2', ' 3 ' e '4', respectivamente.

\subsection{Definir especificações-meta do produto}

A terceira e última atividade a ser proposta para este modelo de abordagem multicritério está representada na Figura 7. Trata-se da atividade de 'Definir especificações-meta do produto'. Destaca-se novamente que as principais informações de entrada para essa atividade são os 'requisitos do produto', obtidos na atividade anterior, ao passo que o resultado, ou entrega, é a lista de 'especificações-meta do produto'.

Depois de definida a completa estrutura, ou hierarquia de objetivos, na atividade anterior, bem como a determinação das taxas de substituição do modelo, a primeira tarefa da atividade de definir as especificações-meta é 'valorar requisitos do produto'. Para esse fim, há dois objetivos como meios para efetuá-la. A primeira envolve 'estabelecer critérios para medir desempenhos'.

Além dos objetivos, uma árvore de valor possui 'atributos' (KEENEY; RAIFFA, 1993; GOODWIN; WRIGHT, 1998), também chamados de 'critérios' (KEENEY, 1992), em seu nível inferior. Esses critérios são obtidos pela análise da cadeia de meios e fins, construídas na primeira tarefa da fase e, então, organizados na hierarquia de objetivos, ou árvores de valor.

Os critérios são estabelecidos para medir os desempenhos dos objetivos mais operacionais, os da extremidade do modelo. Conforme já explicado, o pensamento em busca da obtenção dos meios para se suprir as necessidades dos clientes, conduz a determinadas características que o produto deveria ter. Essas características, enfim, são chamadas de 'critérios' neste trabalho.

Para ilustrar, um dos objetivos meios, relacionados para se atingir a 'eficiência' do produto, diz respeito a 'especificar matéria-prima', para o qual se obtiveram seis possíveis implementações no produto. As preferências do cliente, para esse exemplo, estão organizadas no critério apresentado na Figura 8. 
Contudo, não se pode confundir o conceito de critério, ou atributo, com as ações potenciais das quais ele é composto. Neste exemplo, o critério envolvido é o tipo de 'matéria-prima' e os níveis de desempenho propostos ou ações potenciais das quais esse critério é composto são: 'chapa de aço e PP'; 'chapa de aço e PS'; 'chapa de aço e fibra'; "perfis de aço e PP"; "perfis de aço e PS" e; "perfis de aço e fibra", conforme a Figura 8.

Nesta figura, todos os níveis de desempenho são aceitáveis para o cliente, embora os mais elevados na representação gráfica sejam os preferíveis. O importante é que a atribuição de critérios para medir os objetivos sempre requer juízos de valor (KEENEY, 1992, p. 100). Em consequência, esses juízos de valor podem conduzir a importantes insights e, muitas vezes, alternativas para solucionar partes importantes de um problema de decisão. Isso é especialmente válido em problemas de projeto de produtos, quando os projetistas se veem diante de múltiplas opções de escolha e as dúvidas quanto à implementação de determinadas especificações são frequentes.

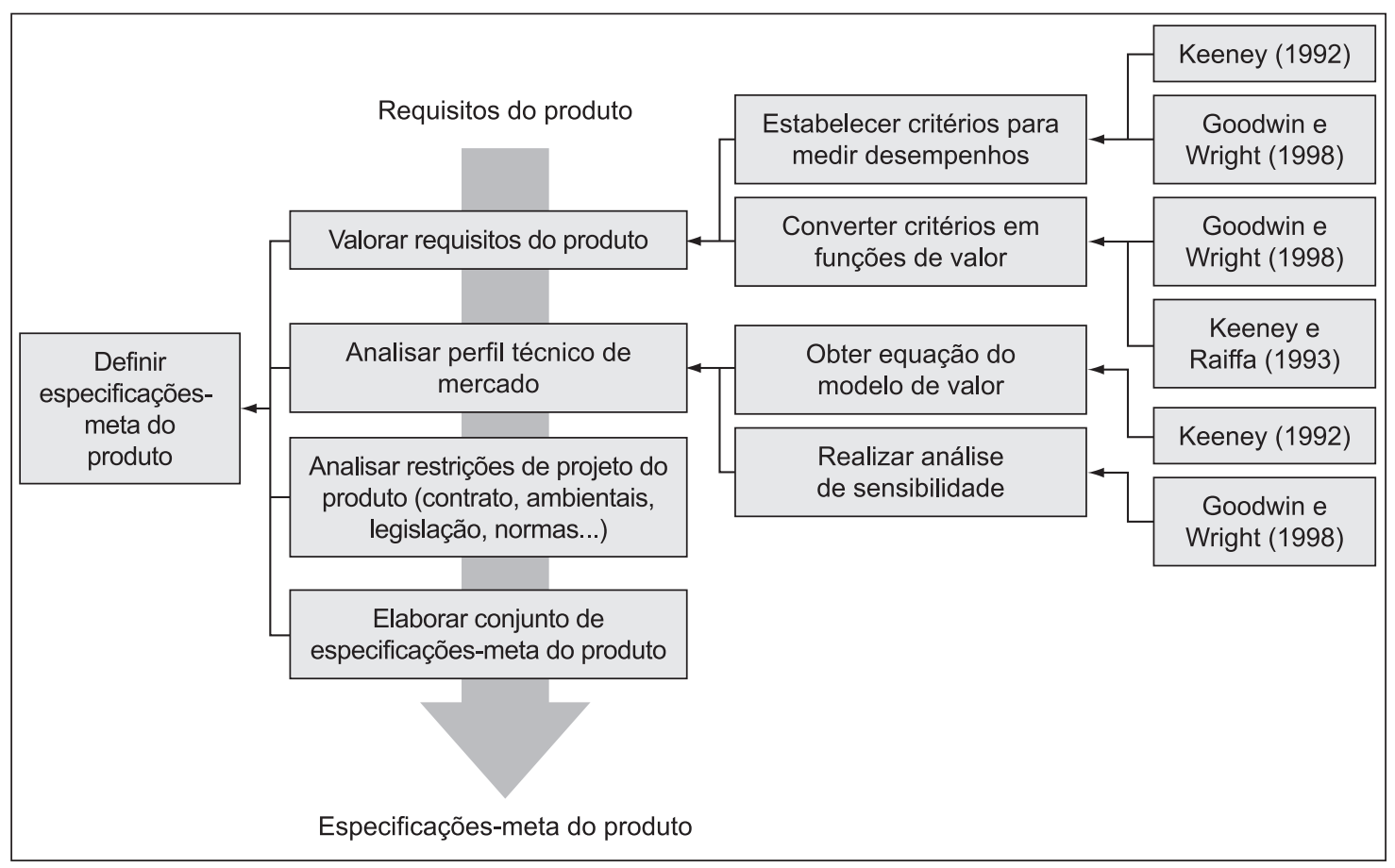

Figura 7. Atividade de 'Definir especificações-meta do produto' com abordagem multicritério.

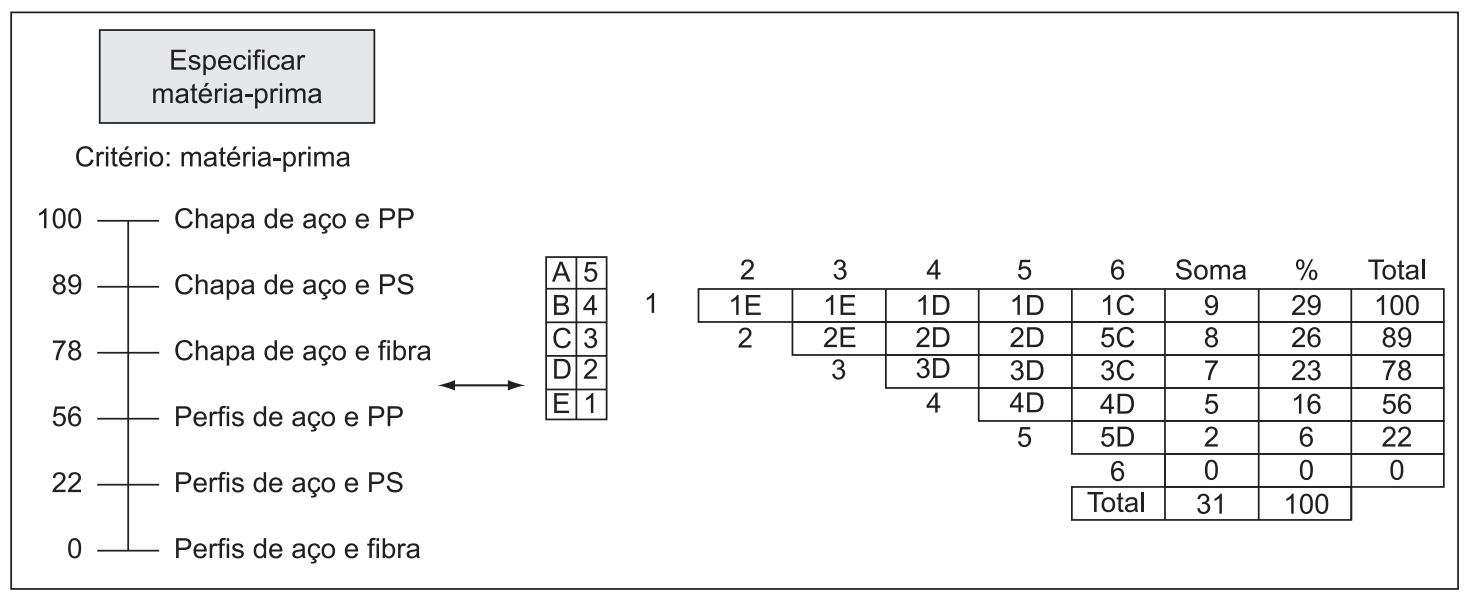

Figura 8. Conversão de um critério para uma função de valor. 
Depois de definida a totalidade dos critérios do modelo, observa-se na Figura 7 que o segundo procedimento para a realização da tarefa de valorar os requisitos do produto é converter os critérios obtidos em 'funções de valor' (KEENEY; RAIFFA, 1993; GOODWIN; WRIGHT, 1998). Portanto, uma vez determinados os critérios do modelo, o decisor deverá, em seguida, codificar suas preferências para estas consequências, em termos de números cardinais de utilidade. Para Keeney e Raiffa (1993), esta medida não só reflete os rankings ordinais do decisor para diferentes consequências, como indica igualmente suas preferências relativas para escolha sobre estas consequências.

Ou seja, no procedimento anterior a equipe de desenvolvimento, em conjunto com o grupo de foco, determinou a ordem em que as opções, ou ações potenciais, de determinado critério, são preferíveis. Contudo, não se sabe ainda o quanto cada opção é desejada, em comparação com as outras. Em outras palavras, não se sabe o grau de importância que a implementação de alguma opção de escolha oferece ao modelo e ao projeto do produto. É exatamente esse o conceito de função de valor. Em termos matemáticos, "uma função ' $v$ ', quando associada a um número real ' $\mathrm{v}(\mathrm{x})$ ' para cada ponto ' $\mathrm{x}$ ' em um espaço de avaliação, diz-se ser uma 'função de valor', representando, assim, a estrutura de preferência do decisor (KEENEY; RAIFFA, 1993).

Para facilitar o entendimento, a Figura 8 ilustra a conversão do critério já construído para uma função de valor.

Nota-se na figura que no nível mais elevado do critério atribui-se o algarismo '100', enquanto que no nível mais inferior atribui-se o algarismo ' 0 '. Esse procedimento se tornará uma convenção para este trabalho, em virtude de simplificar os cálculos, seguindo o modelo de Goodwin e Wright (1998). Outro detalhe, deixado claro na Figura 8 é que, para se obter os níveis intermediários a '0' e '100', propõe-se novamente a utilização do Diagrama de Mudge (ROZENFELD et al., 2006). Assim, para finalizar o procedimento de conversão, a aplicação de uma simples 'regra de três' sobre os valores obtidos no diagrama irá gerar a relativa escala desejada.

Depois de todas as funções de valor do modelo terem sido obtidas, juntando-as aos valores das taxas de substituição, é possível obter-se o 'modelo de valor' do projeto (KEENEY, 1992), expresso em uma equação matemática. Para este trabalho, o resultado da equação é chamado de Índice de Atendimento dos Requisitos (IAR), que indicará o quanto uma determinada solução de projeto ou um produto concorrente corresponde satisfatoriamente aos requisitos de projeto e, consequentemente, às necessidades dos clientes. Esse modelo permitirá, por fim, realizar a próxima tarefa da atividade em questão, descrita na Figura 7, de 'analisar o perfil técnico e de mercado' do produto em desenvolvimento. O modelo de valor do projeto do DASIII é representado pela Equação 1:

$$
\begin{aligned}
& \text { IAR=CE } \times\{0,31 \times[0,25 \times(0,35 \times \\
& \times(100 ; 83 ; 33 \text { ou } 0)+0,65 \times \\
& (100 ; 88 ; 69 ; 31 ; 6 \text { ou } 0))+0,3 \times \\
& (0,75 \times(100 ; 70 ; 20 \text { ou } 0)+0,25 \times \\
& (100 ; 83 ; 67 \text { ou } 0))+0,45 \times(0,5 \times \\
& (100 ; 67 ; 60 ; 33 ; 13 \text { ou } 0)+0,5 \times \\
& (100 ; 73 ; 18 \text { ou } 0))]+0,38 \times[0,08 \times \\
& (100 ; 79 ; 68 ; 53 ; 32 ; 11 \text { ou } 0)+0,4 \times \\
& (100 ; 50 ; 33 \text { ou } 0)+0,2 \times \\
& (100 ; 63 ; 25 \text { ou } 0)+0,2 \times \\
& (100 ; 33 ; 22 \text { ou } 0)+0,12 \times \\
& (100 ; 60 ; 40 \text { ou } 0)]+0,12 \times[0,5 \times \\
& (100 ; 87 ; 47 ; 33 ; 7 \text { ou } 0)+0,3 \times \\
& (100 ; 75 ; 50 ; 38 \text { ou } 0)+0,2 \times \\
& (0,6 \times(100 ; 80 ; 53 ; 40 ; 13 \text { ou } 0)+ \\
& 0,4 \times(100 ; 36 ; 18 \text { ou } 0))]+0,19 \times \\
& {[0,25 \times(100 ; 83 ; 33 ; 17 \text { ou } 0)+} \\
& 0,35 \times(100 ; 77 ; 46 ; 23 \text { ou } 0)+ \\
& 0,4 \times(0,4 \times(100 ; 75 ; 63 ; 50 \text { ou } 0)+ \\
& 0,6 \times(100 ; 70 ; 50 ; 40 ; 30 \text { ou } 0)]\}+ \\
& \text { CII } \times\{0,3 \times[0,29 \times \\
& (100 ; 50 ; 31 ; 25 \text { ou } 0)+0,14 \times \\
& (100 ; 83 ; 75 ; 17 ; 8 \text { ou } 0)+0,21 \times \\
& (100 ; 50 ; 25 \text { ou } 0)+0,36 \times \\
& (100 ; 78 ; 33 \text { ou } 0)]+0,7 \times \\
& {[0,56 \times(100 ; 70 ; 30 \text { ou } 0)+0,13 \times} \\
& (100 ; 67 ; 22 \text { ou } 0)+0,09 \times \\
& (100 ; 89 ; 78 ; 56 ; 22 \text { ou } 0)+0,06 \times \\
& (100 ; 64 ; 27 \text { ou } 0)+0,16 \times \\
& (100 ; 91 ; 55 ; 27 \text { ou } 0)]\} \\
&
\end{aligned}
$$

em que:

$$
\begin{aligned}
& \mathrm{CE}=\text { taxa de substituição de "Clientes Externos"; e } \\
& \mathrm{CII}=\text { taxa de substituição de "Clientes Intermediá- } \\
& \text { rios e Internos". }
\end{aligned}
$$

Um modelo assim, representando o mais próximo possível o ponto de vista dos clientes para o produto em desenvolvimento, servirá de grande auxílio para análises relativas a produtos concorrentes, por exemplo, indicando quais são os desempenhos atuais no mercado, ou status quo (KEENEY, 1992; GOODWIN; WRIGHT, 1998). 
Além da equação, com o modelo também se pôde determinar quais requisitos do projeto possuíam maior valor para os clientes, ao considerar os valores percentuais atribuídos a cada requisito na árvore de valor. Na Tabela 1 , os valores foram calculados e cada requisito, ordenado segundo sua importância para o projeto.

A partir das informações apresentadas na Tabela 1 foi possível gerar um gráfico que confronta os valores que os clientes do DASIII atribuíram aos requisitos com o desempenho atualmente observado em outros emissores eletrônicos de senha da Specto. Ou seja, nessa análise comparativa os requisitos gerados com o modelo foram pontuados levando-se em consideração as necessidades já atendidas por outros produtos da empresa. As funções de valor construídas foram sendo assinaladas conforme o nível que a empresa já atingiu com algum de seus produtos, seu status quo. O resultado encontra-se na Figura 9.

A primeira conclusão deste gráfico, ao observar a dispersão dos requisitos, é que o projeto em questão é bastante peculiar. Basicamente não existem necessidades essenciais a serem atendidas, mas a grande concentração no gráfico ocorre na área que demonstra que os produtos atualmente produzidos pela empresa atendem de maneira muito satisfatória às necessidades levantadas neste projeto específico.

A utilidade maior da análise ficou por conta de auxiliar na percepção de que falta um emissor de senhas com custo mais baixo na linha de produtos. A oportunidade surge com o desenvolvimento do DASIII, a ser produzido com esse objetivo maior,

Tabela 1. Requisitos do projeto em ordem de importância.

\begin{tabular}{|c|c|c|}
\hline Ordem & Requisito de projeto & Importância \\
\hline $1^{\circ}$ & 8) como ocultar impressora & $15,2 \%$ \\
\hline $2^{\circ}$ & 9) layout da interface & $7,6 \%$ \\
\hline $3^{\circ}$ & 10) forma de fixação & $7,6 \%$ \\
\hline $4^{\circ}$ & 3) altura do painel & $7 \%$ \\
\hline $5^{\circ}$ & 5) tamanho de fonte para as opções & $7 \%$ \\
\hline $6^{\circ}$ & 6) área do painel de opções & $7 \%$ \\
\hline $7^{\circ}$ & 17) como fazer manutenção & $6,6 \%$ \\
\hline $8^{\circ}$ & 12) tipo de acionamento & $6 \%$ \\
\hline $9^{\circ}$ & 2) posição de saída da senha & $5 \%$ \\
\hline $10^{\circ}$ & 16) tipo de união entre SSC's & $4,8 \%$ \\
\hline $11^{\circ}$ & 19) materiais & $4,6 \%$ \\
\hline $12^{\circ}$ & 11) dimensões máximas & $4,6 \%$ \\
\hline $13^{\circ}$ & 13) sistema de fechamento & $3,6 \%$ \\
\hline $14^{\circ}$ & 18) projeção de tempo de vida útil & $3 \%$ \\
\hline $15^{\circ}$ & 7) aplicação da cor & $3 \%$ \\
\hline $16^{\circ}$ & 1) tamanho do aviso "retire sua senha" & $2,7 \%$ \\
\hline $17^{\circ}$ & 4) inclinação do pedestal & $2,3 \%$ \\
\hline $18^{\circ}$ & 14) como ocultar fonte & $1,4 \%$ \\
\hline \multirow[t]{2}{*}{$19^{\circ}$} & 15) como ocultar fios & $1 \%$ \\
\hline & Total de "Clientes Externos" & $100 \%$ \\
\hline $1^{\circ}$ & 24) meta de custo de fabricação & $39,2 \%$ \\
\hline $2^{\circ}$ & 28) estilo do produto & $11,2 \%$ \\
\hline $3^{\circ}$ & 23) peso do produto & $10,8 \%$ \\
\hline $4^{\circ}$ & 25) número de componentes & $9,1 \%$ \\
\hline $5^{\circ}$ & 20) previsão de tempo para montagem & $8,7 \%$ \\
\hline $6^{\circ}$ & 22) volume máximo encaixotado & $6,3 \%$ \\
\hline $7^{\circ}$ & 26) matéria-prima & $6,3 \%$ \\
\hline $8^{\circ}$ & 21) estrutura do pedestal & $4,2 \%$ \\
\hline \multirow[t]{2}{*}{$9^{\circ}$} & 27) tipo de impressora & $4,2 \%$ \\
\hline & Total de "Clientes Intermediários e Internos" & $100 \%$ \\
\hline
\end{tabular}


haja vista que o valor que os clientes atribuíram a esse requisito, de 39,2\%, foi elevado em comparação com os demais, causando certa discrepância no gráfico. Desse modo, os esforços nas fases restantes do projeto se concentraram em promover o requisito 'especificar meta de custo de fabricação' de uma situação de oportunidade para uma situação de necessidade essencial para o projeto.

Com o modelo pronto e a metas estabelecidas, o desenvolvimento do DASIII se encaminhou para a fase de Projeto Conceitual. Nessa fase, o modelo multicritério ainda foi de bastante utilidade, dessa vez para analisar as alternativas geradas com base em seus respectivos índices de atendimento dos requisitos a partir do conhecimento construído na fase de Projeto Informacional. Para ilustrar, na Figura 10 observam-se duas das alternativas geradas como conceitos para o emissor de senhas, o conceito 1 e o conceito 2 .

Ambos os conceitos tiveram seus índices, ou pontuação, calculados a partir do modelo multicritério desenvolvido. A Figura 11 apresenta os gráficos gerados para cada um dos conceitos e a pontuação total de cada um, tanto para os requisitos dos clientes externos quanto para os requisitos dos clientes intermediários e internos. As numerações que identificam os requisitos são as mesmas da Tabela 1 .

$\mathrm{O}$ uso da equação gerou os seguintes índices de atendimento dos requisitos: Clientes Externos, igual a 80 (Conceito 1) e 85 (Conceito 2); e Clientes Intermediários e Internos, igual a 91 (Conceito 1) e 62 (Conceito 2). Embora o conceito 1 não atenda tão bem aos requisitos dos clientes externos quanto o conceito 2, o índice obtido nos requisitos dos clientes intermediários e internos foi notavelmente maior.

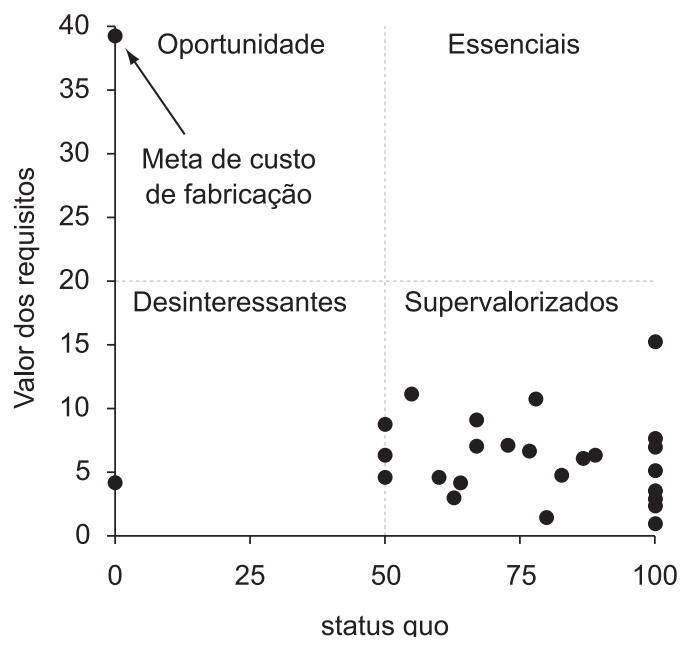

Figura 9. Análise do desempenho de outros produtos da empresa com base nas necessidades do projeto DASIII.

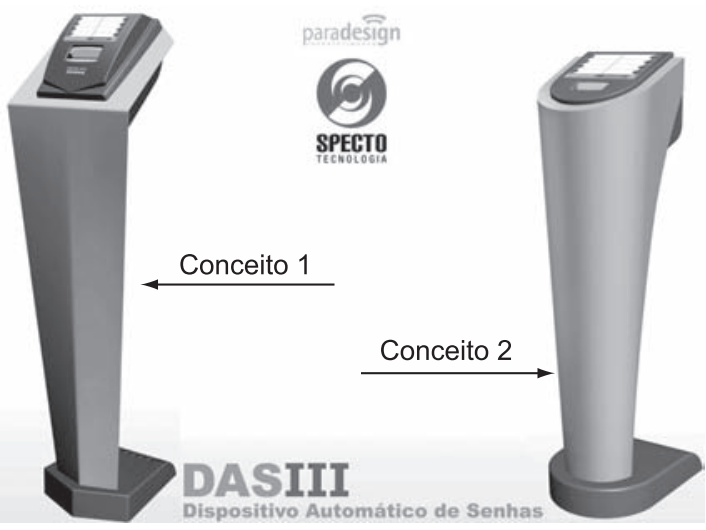

Figura 10. Conceitos para o DASIII.
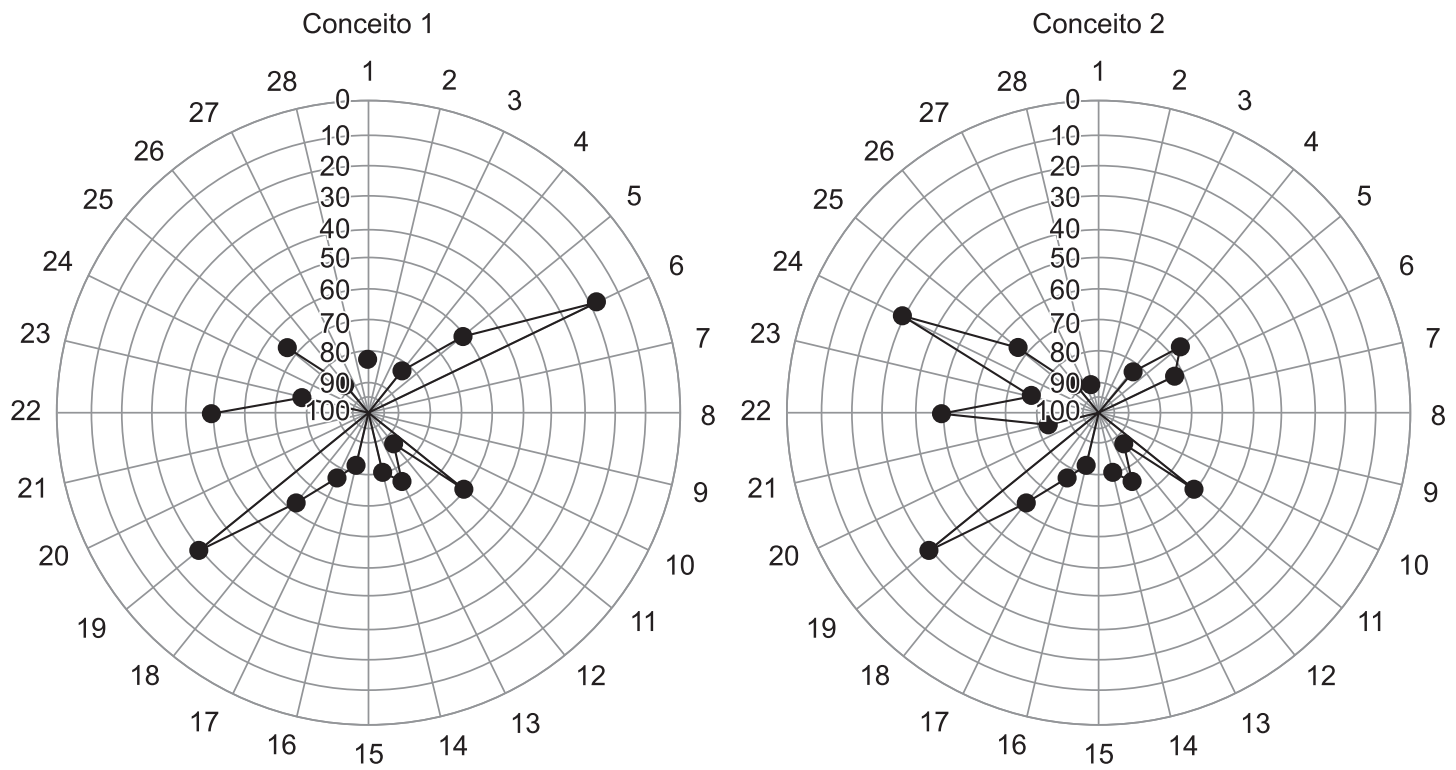

Figura 11. Desempenho dos conceitos para o projeto. 
Ao prosseguir com a análise do perfil técnico e de mercado, chega-se ao último método de apoio para o modelo multicritério desenvolvido. Sugere-se agora a realização da 'análise de sensibilidade' do modelo. Para Goodwin e Wright (1998, p. 35),

a análise de sensibilidade é utilizada para examinar o quão robusta é a escolha de uma alternativa nas mudanças dos valores utilizados na análise.

Essa análise pode, inclusive, ser representada graficamente, o que facilita muito a visualização do equilíbrio matemático, ou tradeoffs (KEENEY, 1992), existente no modelo de valor desenvolvido. Para o projeto do DASIII, a análise de sensibilidade do modelo assumiu uma importância grande para a tomada de decisões.

Finalmente, com base nessas análises, o modelo é refinado e, juntamente com a tarefa seguinte - a de 'analisar restrições de projeto do produto (contrato, ambientais, legislação, normas...)' - apresentada na Figura 7, é possível reunir todo o conhecimento construído até esse momento do projeto e elaborar o conjunto de especificações-meta do produto, o principal objetivo da fase de Projeto Informacional do Processo de Desenvolvimento de Produtos.

\section{Discussão dos resultados}

Nesta seção, apresenta-se a discussão acerca dos benefícios e/ou as vantagens que a abordagem multicritério e o foco no processo de tomadas de decisão oferecem para as primeiras etapas de projeto de produtos, especificamente a fase de Projeto Informacional. A proposta se justifica pelos aspectos que agregam valor ao desenvolvimento, mas que ainda não são contemplados com outras ferramentas e métodos tradicionais do PDP.

Por meio do estudo de caso foi possível esclarecer melhor que métodos, ferramentas e documentos de apoio seriam os mais adequados para a implementação do modelo multicritério, resultando na melhoria do processo de tomada de decisão em projetos de produtos industriais. Para isso, usou-se como plano de fundo o Modelo Unificado de Referência de Rozenfeld et al. (2006), escolhido por se tratar de uma sistematização do PDP das mais recentes e completas.

A primeira atividade contemplada, de 'identificar os requisitos dos clientes do produto', constituiu-se mais em uma preparação para a aplicação direta das práticas multicritério nas duas atividades subsequentes, a saber: 'definir requisitos de projeto do produto' e 'definir especificações-meta do produto'. Os procedimentos que de fato agregaram valor à fase, provenientes da abordagem multicritério, foram os seguintes:

- Uso de mapas mentais com cadeias de meios e fins, para converter os requisitos dos clientes em expressões mensuráveis, ao invés de utilizar matrizes de apoio convencionais propostas na literatura de projeto;

- Construção de árvores de valor com hierarquia de objetivos para analisar e classificar os requisitos do produto gerados, ao invés de utilizar brainstormings e/ou check-lists, obtendo-se, assim, melhor organização e visualização das informações e suas relações;

- Determinar as taxas de substituição da árvore de valor a fim de hierarquizar os requisitos dos clientes e também os requisitos do produto, ao invés de utilizar ou QFD ou outros métodos tradicionais que não permitem observar os tradeoffs do modelo, ou seja, as compensações percentuais que ocorrem entre os requisitos;

- Estabelecer critérios para medir desempenhos e convertê-los em funções de valor a fim de valorar os requisitos do produto, ao invés de limitar as especificações-meta a um valor estático ou simplesmente a uma faixa de valores, mas explicitar que existem níveis de desempenho melhores ou mais críticos; e

- Obter a equação do modelo de valor, com a qual se pôde realizar a análise de sensibilidade, a fim de analisar o perfil técnico e de mercado do produto em desenvolvimento, ao invés de utilizar métodos tradicionais que não realizam essa análise com tanto refinamento e precisão.

Em suma, conclui-se que a realização da fase de Projeto Informacional apoiada pela abordagem multicritério oferece diferenciais importantes em um momento de desenvolvimento tão delicado e no qual as decisões devem ser apoiadas de tal forma a minimizar as chances de erro como em nenhuma outra fase do desenvolvimento de um produto industrial.

\section{Conclusão}

A conclusão imediata que este trabalho pôde explicitar foi que a fase de Projeto Informacional é a mais crítica do Processo de Desenvolvimento de Produtos quanto à complexidade de sua execução e quanto ao nível de importância das decisões de projeto tomadas. Não é surpresa, portanto, que um produto desenvolvido sem consultas constantes e profundas com seus clientes tenha os riscos de não obter sucesso comercial ampliados, independentemente de quão competente seja a realização das demais fases de projeto.

Basicamente, duas linhas de pesquisa relacionam-se diretamente com o conteúdo deste artigo: 1) trabalhos relacionados à prática de projeto e ao processo decisório, que visem integrar a abordagem multicritério com o Processo de Desenvolvimento de Produtos e; 2) trabalhos que, em geral, definam a fase de Projeto 
Informacional como delimitação de pesquisa, visando a melhoria contínua do desenvolvimento.

Recomenda-se, por exemplo, estudar a viabilidade de aplicação da abordagem multicritério para outras fases do PDP. Uma interessante proposta seria dar continuidade ao modelo deste trabalho assim como, por exemplo, ao do QFD que também pode ser desdobrado para outras etapas do desenvolvimento de um produto. Sistematizar o desenvolvimento de produtos com base na abordagem multicritério desde o pré-desenvolvimento até as fases que envolvam a produção e o pós-desenvolvimento, contribuiria para que as atividades fossem mais contínuas e padronizadas. Imagina-se que um trabalho assim possa adicionar as vantagens específicas da abordagem multicritério ao gerenciamento de todo o ciclo de vida dos produtos.

Portanto, espera-se que este trabalho tenha contribuído para sistematizar a atividade de coleta, análise e organização das informações obtidas na fase de Projeto Informacional, ao considerar o tratamento de tais informações como o que ele realmente é: um processo de negócio que envolve múltiplos critérios de escolha, incertezas nas decisões e que precisa ser apoiado com as melhores práticas existentes.

\section{Agradecimentos}

À empresa Specto, em nome do Sr. Leônidas Vieira Júnior, pelas contribuições para o estudo de caso realizado.

\section{Referências}

AAKER, D.; KUMAR, V.; DAY, G. S. Pesquisa de marketing. São Paulo: Atlas, 2001.

BALBIM Jr., A. et al. O modelo MCDA como instrumento de identificação das necessidades do consumidor no processo de desenvolvimento do design de um automóvel. In: CONGRESSO BRASILEIRO DE PESQUISA \& DESENVOLVIMENTO EM DESIGN - P\&D, 8., 2008, São Paulo. Anais... 2008a.
BALBIM Jr., A. et al. Processo para desenvolver inovação no design de produtos: estudo de caso para um automóvel. In: SIMPÓSIO DE GESTÃO DA INOVAÇÃO TECNOLÓGICA, 25., 2008, Brasília, DF. Anais... 2008b.

BAXTER, M. Product design: a pratical guide to systematic methods of new product development. London: Chapman \& Hall, 1995.

FONSECA, A. J. H. Sistematização do processo de obtenção das especificações de projeto de produtos industriais e sua implementação computacional. 2000. 199 f. Tese (Doutorado em Engenharia Mecânica)-UFSC, Florianópolis, 2000.

GOMES FERREIRA, M. G. Utilização de modelos para a representação de produtos no projeto conceitual. 1997. 140 f. Dissertação (Mestrado em Engenharia Mecânica)-UFSC, Florianópolis, 1997.

GOODWIN, P.; WRIGHT, G. Decision analysis for management judgment. 2 ed. Chichester: J. Wiley, 1998.

KEENEY, R. L. Value-focused thinking: a path to creative decisionmaking. Cambridge, Mass.: Harvard University, 1992.

KEENEY, R. L.; RAIFFA, H. Decisions with multiple objectives: preferences and value tradeoffs. New York: Cambridge University Press, 1993.

OTTO, K. N.; WOOD, K. L. Product design - techniques in reverse engineering and new product development. New Jersey: Prentice Hall, 2001.

PAHL, G.; BEITZ, W. Engineering design: a systematic approach. 2 ed. London: Springer, 1996.

PUGH, S. Total design: integrated methods for successful product engineering. Massachusetts: Addison-Wesley, 1990.

RAIFFA, H. Teoria da decisão: aulas introdutórias sobre escolhas em condições de incerteza. Petrópolis: Vozes, 1977.

ROOZENBURG, N. F. M.; EEKELS, J. Product design fundamentals and methods. Chichester: Wiley, 1995.

ROZENFELD, H. et al. Gestão de desenvolvimento de produtos: uma referência para a melhoria do processo. São Paulo: Saraiva, 2006.

STEPHAN, A. P. et al. (Cord.). 10 cases do design brasileiro: os bastidores do processo de criação. São Paulo: Blucher, 2008. 